\title{
Infusion of the NMDA receptor antagonist, DL-APV, into the basolateral amygdala disrupts learning to fear a novel and a familiar context as well as relearning to fear an extinguished context
}

\author{
Vincent Laurent and R. Frederick Westbrook ${ }^{1}$ \\ School of Psychology, The University of New South Wales, Sydney, New South Wales 2052, Australia
}

\begin{abstract}
Ample evidence suggests that activation of NMDA receptors (NMDAr) in the basolateral complex of the amygdala (BLA) is necessary for context fear conditioning. The present series of experiments examined whether this activation was still required when the to-be-shocked context had a history. We found that BLA infusion of the selective NMDAr antagonist DL-APV impaired the acquisition of fear responses to a novel context, a moderately familiar context, or a highly familiar context. The same treatment also impaired the reacquisition of fear responses to a dangerous context, a context extinguished to criterion, or a context massively extinguished. Importantly, DL-APV persistently suppressed fear responses, suggesting that the NMDAr antagonist disrupted basal synaptic transmission in the BLA. Therefore, we conclude that neuronal activity in the BLA is critical for learning and relearning context-conditioned fear. This finding is consistent with current neural models that attribute context fear conditioning to interactions among several brain regions, most notably the hippocampus and the BLA.
\end{abstract}

Activation of $\mathrm{N}$-methyl-D-aspartate receptors (NMDAr) is critical for many forms of learning (Riedel et al. 2003). One example is the use of spatial information to locate the hidden platform in the Morris maze. Learning to use this information is impaired by intracerebroventricular (i.c.v) infusion of the NMDAr antagonist DL-APV (Morris 1989; Bannerman et al. 1995). A second example is the acquisition and extinction of Pavlovian conditioned fear responses. Acquisition occurs in subjects exposed to a context or stimulus paired with an aversive unconditioned stimulus (US), while extinction occurs when they are repeatedly exposed to the conditioned context or stimulus (CS) in the absence of the aversive US. The acquisition of such fears and their inhibition by the learning produced by extinction are each disrupted by infusion of DL-APV into the basolateral complex of the amygdala (BLA) (Miserendino et al. 1990; Campeau et al. 1992; Maren et al. 1996; Lee and Kim 1998; Lee et al. 2001; Laurent et al. 2008). Infusion of DL-APV into the dorsal hippocampus spares acquisition of fears to a CS paired with shock while disrupting acquisition to the context where the pairings occurred (Sanders and Fanselow 2003; Quinn et al. 2005). These findings suggest that activation of NMDAr in various brain regions is necessary to trigger the signal transduction cascade that leads to the long-term stabilization of spatial, fear, and fear inhibition memories (Martin et al. 2000; Blair et al. 2001; Myers and Davis 2007).

Nevertheless, there is also evidence that components of the learning produced by these tasks can occur under blockade of NMDAr. For instance, rats that had learned to locate a hidden platform in one Morris maze were able to use spatial information to locate a hidden platform in a second maze in spite of the fact that training in the second maze occurred under an i.c.v infusion of DL-APV (Bannerman et al. 1995). Similarly, rats that had learned to fear one context acquired fear of a second context in

\footnotetext{
'Corresponding author.
}

E-mail f.westbrook@unsw.edu.au; fax 61-92-03853044.

Article is online at http://www.learnmem.org/cgi/doi/10.1101/lm.1218709. spite of the fact that pairings of this second context with a shock US occurred under an intrahippocampal infusion of DL-APV (Sanders and Fanselow 2003). Thus, learning that a hidden platform is located by the use of spatial cues or that a context is dangerous allows subsequent learning of such tasks independent of NMDAr activation. Learning to inhibit context-conditioned fear responses in extinction is disrupted by an intra-BLA infusion of DL-APV, but relearning this inhibition occurs in spite of the fact that this second extinction occurs under an infusion of DL-APV into the BLA (Laurent et al. 2008). More specifically, rats were trained to fear a context, and this fear was extinguished. They were again trained to fear that context, and this fear was again extinguished. Rats that received this second extinction under an infusion of DL-APV into the BLA exhibited low levels of fear on a subsequent retention test, whereas those receiving an initial extinction under that infusion showed substantial levels of fear on the retention test. Thus, learning to inhibit fear responses to a context allowed relearning inhibition of fear responses to the same context in spite of the fact that the second extinction occurred under a BLA infusion of DL-APV.

Although relearning inhibition of context-conditioned fear can occur under an infusion of DL-APV into the BLA, learning to fear a context was disrupted by such an infusion in rats that had previously learned to fear a different context (Lee and Kim 1998). Learning to fear one context did not remove the necessity to recruit NMDAr in the BLA when subsequently learning to fear a different context. One difference between these studies was that DL-APV was infused into the BLA among rats subjected to a second extinction in the context where the initial extinction had occurred, whereas it was infused into the BLA among rats receiving their second fear-conditioning episode in a different context from that already conditioned. Therefore, one possible explanation for the contrasting effects of an intra-BLA infusion on relearning to fear a context or relearning to inhibit such fear is whether subjects are required to learn to fear a new context or to learn anew about an already familiar context. It has been demonstrated that the 
molecular mechanisms necessary to learn an aversion to a familiar stimulus differ from those necessary to learn an aversion to a novel stimulus (Berman and Dudai 2001). Activation of mitogenactivated protein kinase and muscarinic receptors in the insular cortex are necessary for the formation of the aversive memory to a novel taste but not a familiar one. Accordingly, NMDAr activation in the BLA might be required for learning to fear a new context but not learning to fear a familiar one.

The present series of experiments studied the effects of a BLA infusion of DL-APV on the acquisition and reacquisition of fear responses to a context in rats. It had two aims. The first was to determine whether an infusion of DL-APV into the BLA disrupts acquisition of fear to a familiar context just as such an infusion disrupts acquisition to a relatively novel context. The second aim was to determine whether an infusion of DL-APV into the BLA disrupts reacquisition of fear to a context conditioned and extinguished just as such an infusion disrupts the acquisition of fear responses to a context in rats conditioned to a different context. Experiments 1 and 2 studied the influence of familiarity on context fear conditioning. Rats were trained to fear a moderately (Experiment 1) or a massively (Experiment 2) familiar context under BLA infusion of the selective NMDAr antagonist, DL-APV, or vehicle. Experiments 3 and 4 studied the role of task familiarity. Rats were trained to fear a context and their fear responses extinguished to either a criterion (Experiment 3) or subjected to additional (massive) extinction (Experiment 4). Control rats were simply trained to fear the context but did not receive extinction. Then, all rats were retrained to fear the context under BLA infusion of DL-APV or vehicle. Across all experiments, all rats were tested drug-free for retention of the learning produced by the contextshock pairing that occurred under drug or vehicle.

\section{Results}

\section{Experiment 1: BLA infusion of DL-APV impairs learning to fear a briefly pre-exposed context}

Previous investigations have shown that infusion of DL-APV in the BLA reduces fear responses and impairs acquisition of conditioned fear to a CS paired with shock as well as the context where shock occurs (Maren et al. 1996; Lee and Kim 1998; Fendt 2001; Lee et al. 2001; Jasnow et al. 2004). We examined whether such an infusion impairs acquisition of fear responses to a moderately familiar context. Rats were bilaterally implanted with cannulas targeting the BLA and were randomly assigned to one of the two experimental conditions (see Fig. 2A). Rats in Group Brief Preexposure were exposed to distinctive chambers for $2 \mathrm{~min}$ each day across four consecutive days, while those in Groups No Preexposure were handled on these days but not exposed to the chambers. On Day 5, all rats were infused in the BLA with either DL-APV (Group No Pre-exposure - APV and Group Brief Preexposure - APV) or vehicle (Group No Pre-exposure - Vehicle and Group Brief Pre-exposure - Vehicle). Immediately after, rats were placed in the chambers and administered a foot shock 1 min later. They remained in the chambers for 2 min after shock. On Day 6, rats were tested drug-free for fear responses (freezing) in the chambers.

\section{Histology}

Figure 1A shows the approximate location of injection cannula tips. A total of seven rats were excluded because of incorrect placement. This yielded the following group sizes: Group No Preexposure - Vehicle $(n=8)$, Group No Pre-exposure - APV $(n=8)$, Group Brief Pre-exposure - Vehicle $(n=8)$, and Group Brief Preexposure - APV $(n=7)$.

\section{Behavior}

Levels of freezing to the context across conditioning and test are shown in Figure 2. Levels of pre-shock freezing were very low $(<5 \%)$, and there were no differences between groups (Fig. 2B, left panel). Brief pre-exposures to the context increased levels of freezing in the post-shock period (Fig. 2B, right panel) as rats in Group Brief Pre-exposure - Vehicle froze significantly more than rats in Group No Pre-exposure - Vehicle $\left(F_{(1,27)}=11.400, P<0.05\right)$. DL-APV reduced fear responses. Rats treated with DL-APV (Groups No Pre-exposure - APV and Brief Pre-exposure - APV) froze significantly less than rats treated with vehicle (Group No Preexposure - Vehicle and Group Brief Pre-exposure - Vehicle; $F_{(1,42)}=$ $82.915, P<0.05)$. There were no significant differences between the two groups of APV-treated rats $\left(F_{(1,42)}=1.628, P>0.05\right)$.

The retention test data (Fig. 2C) shows that infusing DL-APV in the BLA impaired the acquisition of fear responses to both a novel and a briefly pre-exposed context. Rats in Group No Preexposure - APV and Group Brief Pre-exposure - APV froze significantly less than rats treated with vehicle $\left(F_{(1,27)}=22.092\right.$, $P<0.05)$. Brief pre-exposures to the context did not remove the impairment produced by DL-APV as there were no differences between the two groups of rats treated with the NMDAr antagonist $\left(F_{(1,27)}=0.918, P>0.05\right)$. Consistent with previous findings, brief pre-exposures facilitated context fear conditioning (Fanselow 1990; Kiernan and Westbrook 1993; Wiltgen et al. 2001). Rats in Group Brief Pre-exposure - Vehicle froze significantly more than rats in Group No Pre-exposure - Vehicle $\left(F_{(1,27)}=8.577, P<0.05\right)$, showing that rats had learned about the context across preexposure. Nevertheless, this learning was not sufficient to support fear acquisition when rats were subsequently shocked in that context under a BLA infusion of DL-APV.

\section{Experiment 2: BLA infusion of DL-APV impairs learning to fear a massively pre-exposed context}

Experiment 1 showed that BLA infusion of DL-APV impairs learning to fear a novel and a moderately familiar context. The present experiment examined whether the same conclusion applied to learning to fear a highly familiar context (Fig. 3A). Half of the rats (Groups Massive Pre-exposure) were exposed to the chambers in the absence of shock for $2 \times 20$ min each day across 11 consecutive days. On Day 12, all rats were shocked in the chambers in the manner described previously. Rats in Group No Pre-exposure - APV and Group Massive Pre-exposure - APV were infused with DL-APV in the BLA immediately before the shocked exposure whereas those in Group No Pre-exposure - Vehicle and Group Massive Pre-exposure - Vehicle were infused with vehicle. Fourteen days later, levels of fear responses were assessed across a retention test conducted drug-free. A retention interval between conditioning and test was inserted as previous studies reported that rats conditioned in a massively pre-exposed context showed little freezing when tested in the context $1 \mathrm{~d}$ later, but substantial levels of freezing when tested $14 \mathrm{~d}$ after conditioning (Killcross et al. 1998; Leung et al. 2007).

\section{Histology}

Figure $1 \mathrm{~B}$ shows the approximate location of injection cannula tips. A total of nine rats were excluded because of incorrect placement. This yielded the following group sizes: Group No Pre-exposure - Vehicle $(n=8)$, Group No Pre-exposure - APV $(n$ $=8)$, Group Massive Pre-exposure - Vehicle $(n=8)$, and Group Massive Pre-exposure - APV $(n=9)$.

\section{Behavior}

Levels of conditioned freezing to the context across conditioning and test are shown in Figure 3. During conditioning on Day 12, levels of pre-shock freezing were very low $(<5 \%)$, and there were 
A

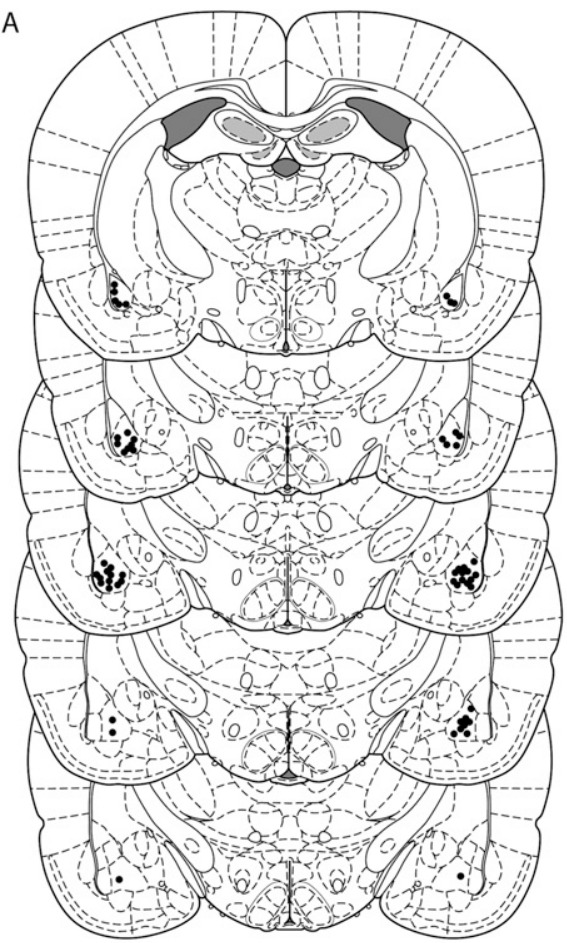

C

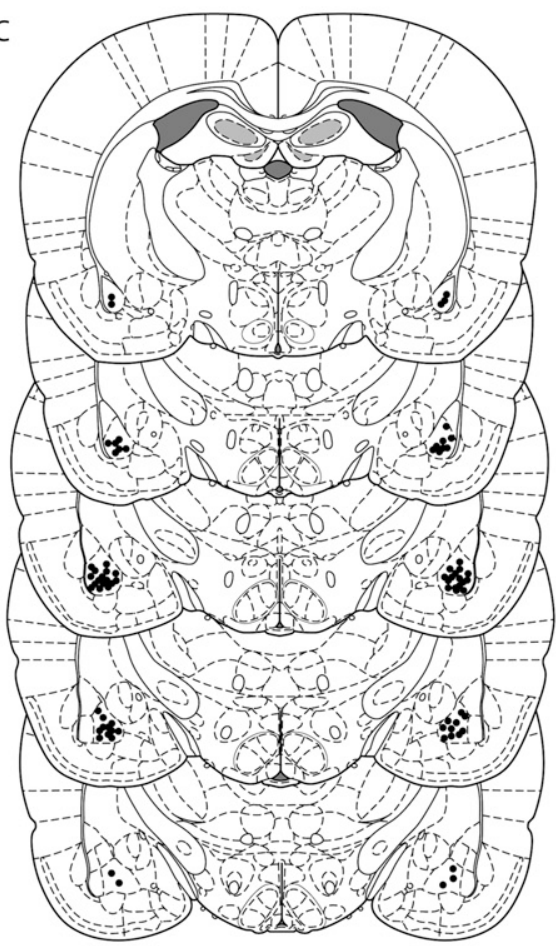

B

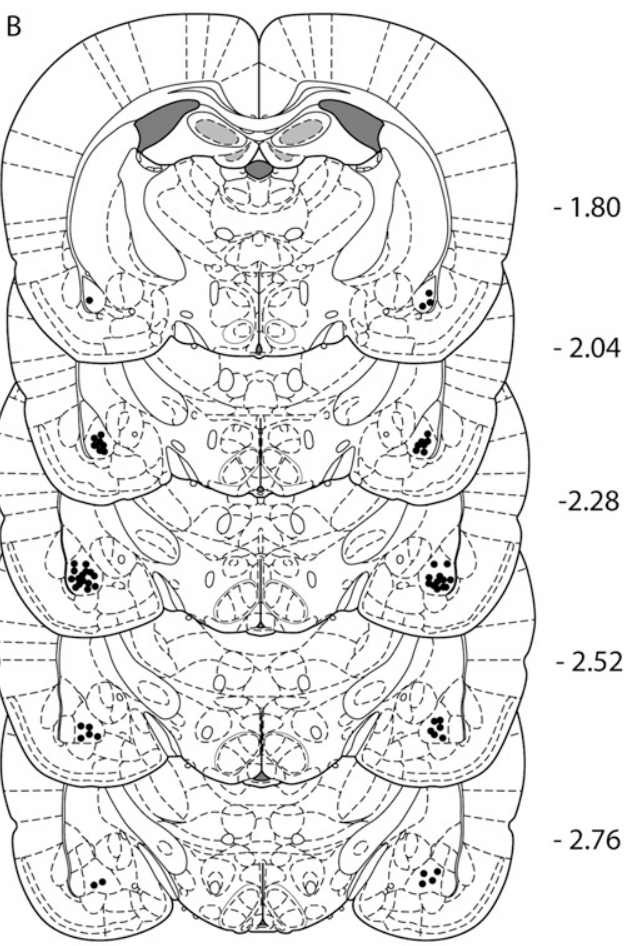

$\mathrm{D}$

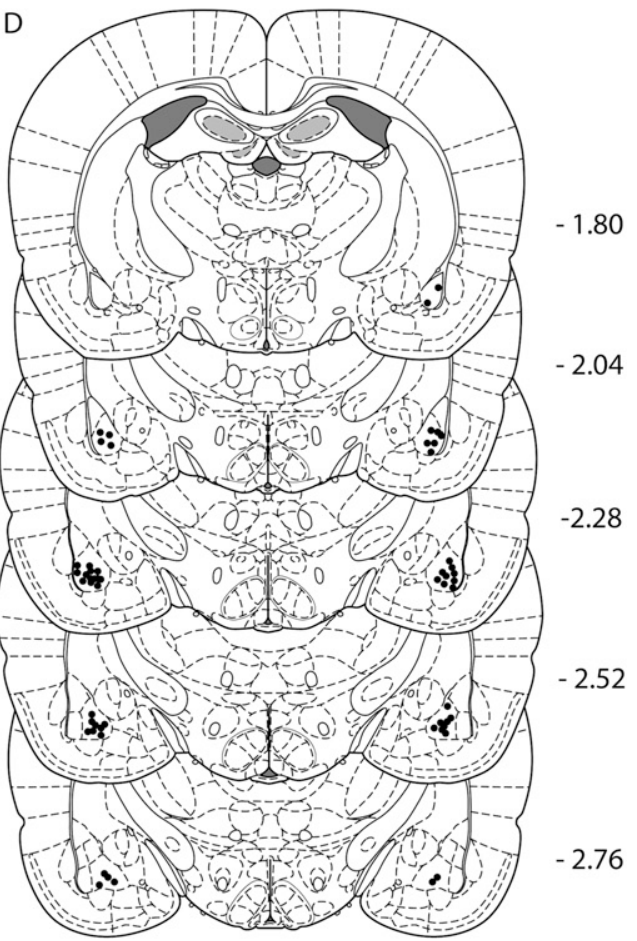

Figure 1. Approximate location of injection cannula tips within the BLA for all rats included in the final analysis of Experiments $1(A), 2(B), 3(C)$, and 4(D). Distances on the atlas templates (adapted from Paxinos and Watson 2007, and reprinted with permission from Elsevier (2007) are indicated in millimeters from bregma.

no differences between groups (Fig. 3B, left panel). Massive preexposures to the context reduced the levels of post-shock freezing (Fig. 3B, right panel). Rats in Group No Pre-exposure - Vehicle froze significantly more than rats in Group Massive Pre-exposure Vehicle $\left(F_{(1,29)}=13.971, P<0.05\right)$. DL-APV reduced fear responses. Rats in Group No Pre-exposure - APV and Group
Massive Pre-exposure - APV spent less time freezing than vehicletreated rats $\left(F_{(1,29)}=8.914, P<0.05\right)$. There were no significant differences between the two groups of rats infused with DL-APV $\left(F_{(1,29)}=0.192, P>0.05\right)$.

The retention test data (Fig. 3C) revealed that DL-APV impaired the acquisition of fear responses to a novel and a highly 
A

\begin{tabular}{|c|c|c|c|c|}
\hline Groups & Day $1-4$ & & & Day 6 \\
\hline $\begin{array}{l}\text { No pre-exposure } \\
\text { (NPE) }\end{array}$ & & $\begin{array}{l}\text { VEH } \\
\text { APV }\end{array}$ & $C x+$ & $C x-$ \\
\hline $\begin{array}{l}\text { Brief pre-exposure } \\
\text { (BPE) }\end{array}$ & $2^{\prime} \mathrm{Cx}-$ & $\begin{array}{l}\text { VEH } \\
\text { APV }\end{array}$ & $\mathrm{Cx}+$ & Cx- \\
\hline
\end{tabular}

B

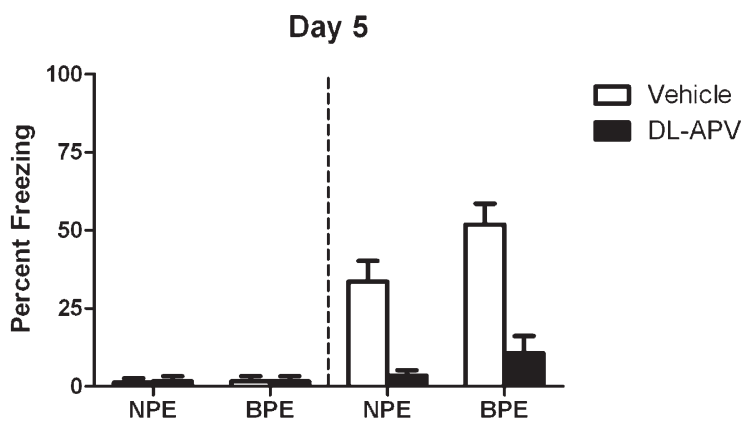

C

Day 6

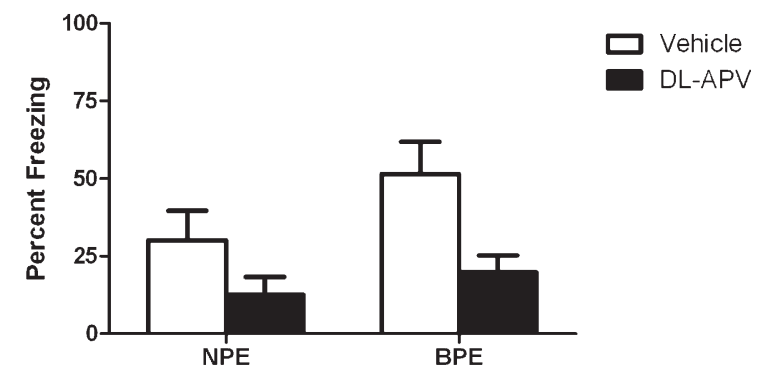

Figure 2. BLA infusion of DL-APV impairs learning to fear a briefly pre-exposed context. (A) Description of the behavioral procedures used in Experiment $1(\mathrm{Cx}+$ indicates shocked exposure to the chambers; $\mathrm{Cx}-$, nonshocked exposure to the chambers; VEH, Vehicle; and APV, DL-APV). (B) All illustrations show the mean and SEM levels of freezing. There was no significant difference in levels of freezing before the shock given on Day 5 (left panel). Rats infused in the BLA with vehicle before conditioning froze more if they had been briefly pre-exposed to the context (right panel; Group Brief Pre-exposure - Vehicle vs. Group No Pre-exposure - Vehicle). BLA infusion of DL-APV suppressed fear responses (Group Brief Pre-exposure - APV and Group No Pre-exposure - APV). (C) The retention test showed that DL-APV disrupted acquisition of fear responses to a novel or moderately familiar context (Group Brief Pre-exposure - APV and Group No Pre-exposure - APV). However, brief pre-exposures facilitated subsequent acquisition of context-conditioned fear (Group Brief Pre-exposure - Vehicle vs. Group No Pre-exposure - Vehicle).

familiar context. Rats in Group No Pre-exposure - APV and Group Massive Pre-exposure - APV froze significantly less than rats in Group No Pre-exposure - Vehicle and Group Massive Pre-exposure - Vehicle $\left(F_{(1,29)}=12.589, P<0.05\right)$. There were no significant differences between the two groups of APV-treated rats $\left(F_{(1,29)}=\right.$ $1.158, P>0.05)$ or between the two groups of vehicle-treated rats $\left(F_{(1,29)}=1.424, P>0.05\right)$. Thus, consistent with previous findings, conditioning a massively pre-exposed context supported just as much freezing as did conditioning a novel context when testing occurred after a long retention interval. However, conditioning of either context was disrupted by an infusion of DL-APV into the BLA.

\section{Experiment 3: BLA infusion of DL-APV impairs} relearning to fear a context extinguished to criterion Experiments 1 and 2 revealed that BLA infusion of DL-APV impairs learning to fear a novel, a moderately familiar, and a highly familiar context. The present experiment studied whether DL-APV also impaired reacquisition of fear to a context (Fig. 4A). Two groups of rats (Groups Additional Acquisition and Reacquisition) were shocked in the chambers on Day 1. Rats in Groups Reacquisition were twice daily exposed to the chambers in the absence of the shock on Days 2 and 3. This procedure was sufficient to produce a selected extinction criterion that was defined as less than 5\% of freezing across the first minute of the last extinction session. On Day 4, all rats were infused in the BLA with either DL-APV (Group Initial Acquisition - APV, Group Additional Acquisition - APV, and Group Reacquisition - APV) or vehicle (Group Initial Acquisition - Vehicle, Group Additional Acquisition - Vehicle, and Group Reacquisition - Vehicle). Immediately after infusions, all rats were shocked in the chambers. Finally, rats were tested for fear responses to the chambers on Day 5.

\section{Histology}

Figure 1C shows the approximate location of injection cannula tips. A total of seven rats were excluded because of incorrect placement. This yielded the following group sizes: Group Initial Acquisition - Vehicle $(n=6)$, Group Initial Acquisition - APV $(n=8)$, Group Additional Acquisition - Vehicle $(n=6)$, Group Additional Acquisition - APV ( $n=$ $6)$, Group Reacquisition - Vehicle $(n=7)$, and Group Reacquisition - APV $(n=7)$.

\section{Behavior}

Levels of conditioned freezing to the context are shown in Figure 4. Conditioning on Day 1 was successful. Rats in Groups Reacquisition showed substantial levels of freezing when returned to the chambers for extinction on Day 2 (data not shown). Extinction was successful. Levels of freezing during the first minute of each extinction session significantly decreased from one session to another $\left(F_{(1,12)}=63.484, P<0.05\right)$, and there was no significant difference between rats in Groups Reacquisition $\left(F_{(1,12)}=0.070, P>\right.$ $0.05)$. Rats reached the extinction criterion of less than $5 \%$ freezing by the second session of Day 3 (data not shown). Levels of freezing prior to the shock given on Day 4 (Fig. 4B, left panel) revealed that extinction was retained and that conditioning on Day 1 was successful for rats in Group Additional Acquisition Vehicle. These rats froze significantly more than rats in Group Reacquisition - Vehicle $\left(F_{(1,34)}=90.134, P<0.05\right)$ and Group Initial Acquisition - Vehicle $\left(F_{(1,34)}=88.693, P<0.05\right)$. There were no significant differences between rats in Group Reacquisition Vehicle and Group Initial Acquisition - Vehicle $\left(F_{(1,34)}=0.078, P>\right.$ 0.05). Importantly, DL-APV reduced fear responses prior to the shock. Rats infused with vehicle in the BLA spent more time freezing than APV-treated rats $\left(F_{(1,34)}=79.681, P<0.05\right)$. The administration of the shock did not restore the fear responses reduced by extinction or DL-APV (Fig. 4B, right panel). Rats 
A

\begin{tabular}{lllll}
\hline Groups & Day 1-11 & \multicolumn{2}{c}{ Day 12 } & Day 26 \\
\hline $\begin{array}{l}\text { No pre-exposure } \\
\text { (NPE) }\end{array}$ & & $\begin{array}{l}\text { VEH } \\
\text { APV }\end{array}$ & Cx & Cx- \\
$\begin{array}{l}\text { Massive pre- } \\
\text { exposure (MPE) }\end{array}$ & {$\left[2 \times 20^{\prime}\right] \mathrm{Cx}-$} & $\begin{array}{l}\text { VEH } \\
\text { APV }\end{array}$ & $\mathrm{Cx}+$ & $\mathrm{Cx}-$ \\
\hline
\end{tabular}

B

Day 12

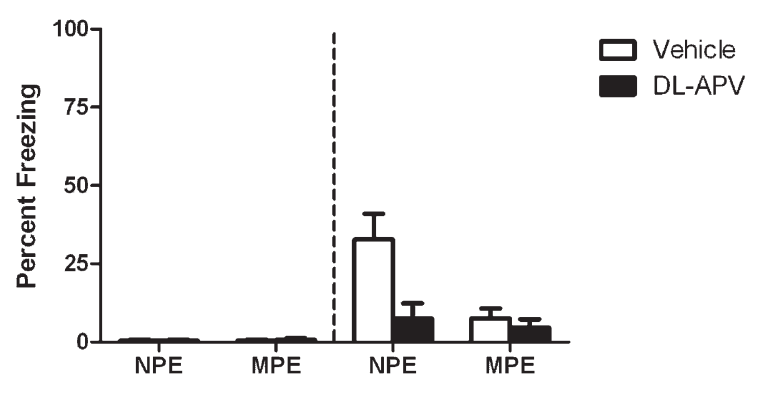

C

Day 26

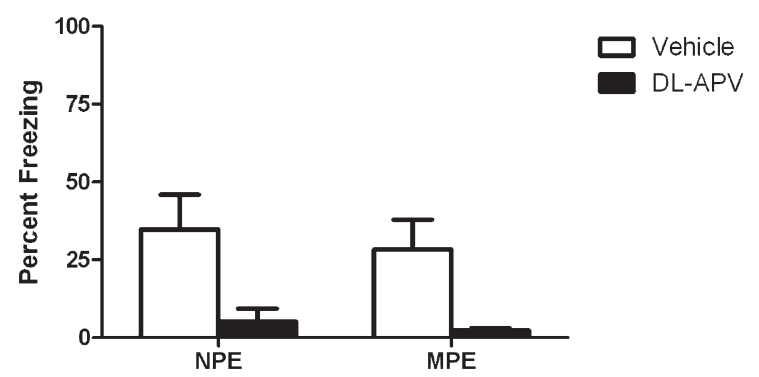

Figure 3. BLA infusion of DL-APV impairs learning to fear a massively pre-exposed context. $(A)$ Description of the behavioral procedures used in Experiment $2(\mathrm{Cx}+$ indicates shocked exposure to the chambers; $\mathrm{CX}_{-}$, nonshocked exposure to the chambers; VEH, Vehicle; and APV, DL-APV). (B) There was no significant difference in levels of freezing before the shock given on Day 13 (left panel). Rats infused in the BLA with vehicle before conditioning froze less if they had been massively pre-exposed to the context (right panel; Group Massive Pre-exposure - Vehicle vs. Group No Pre-exposure - Vehicle). BLA infusion of DL-APV suppressed fear responses (Group Massive Pre-exposure - APV and Group No Preexposure - APV). (C) The retention test showed that DL-APV disrupted acquisition of fear responses to a novel or a highly familiar context (Group Brief Pre-exposure - APV and Group No Pre-exposure APV). Massive pre-exposures did not disrupt subsequent acquisition of context-conditioned fear when rats were tested $14 \mathrm{~d}$ after conditioning (Group Massive Pre-exposure - Vehicle vs. Group No Preexposure - Vehicle).

infused with DL-APV froze less than vehicle-treated rats $\left(F_{(1,34)}=\right.$ 180.552, $P<0.05)$. Rats in Group Additional Acquisition - Vehicle froze significantly more than rats in Group Reacquisition Vehicle $\left(F_{(1,34)}=11.449, P<0.05\right)$ and Groups Initial Acquisition Vehicle $\left(F_{(1,34)}=31.95, P<0.05\right)$. There were no differences between rats in Group Reacquisition - Vehicle and Group Initial Acquisition - Vehicle $\left(F_{(1,34)}=6.168, P>0.05\right)$.

The test data (Fig. 4C) showed that BLA infusion of DL-APV prevented the acquisition of fear responses to a novel context, a feared context, and a context extinguished to criterion. Rats infused with DL-APV froze significantly less than rats infused with vehicle $\left(F_{(1,34)}=88.017, P<0.05\right)$. Stimulus or task familiarity with the context did not remove this impairment, as there was no significant difference between the three groups of APV-treated rats ( $F \mathrm{~s}<0.5$ ). This experiment failed to replicate the findings obtained in another study (Leung et al. 2007). That is, reacquisition after criterion extinction was not facilitated. Rats in Group Reacquisition - Vehicle froze significantly less that rats in Group Additional
Acquisition - Vehicle $\left(F_{(1,34)}=27.982, P\right.$ $<0.05)$ and just as much as rats in Group Initial Acquisition $\left(F_{(1,34)}=0.391, P<\right.$ 0.05).

Experiment 4: BLA infusion of DLAPV impairs relearning to fear a massively extinguished context Experiment 3 demonstrated that BLA infusion of DL-APV impairs relearning to fear a previously feared context or a context extinguished to criterion. In Experiment 4, we examined whether the same conclusion applied to relearning to fear a massively extinguished context (Fig. 5A). Two groups of rats (Groups Additional Acquisition and Reacquisition) were shocked in distinctive chambers on Day 1. Fear responses were then massively extinguished for rats in Groups Reacquisition across 11 consecutive days. On Day 13, all rats were infused in the BLA with either DL-APV (Group Initial Acquisition - APV, Group Additional Acquisition - APV, and Group Reacquisition - APV) or vehicle (Group Initial Acquisition - Vehicle, Group Additional Acquisition - Vehicle, and Group Reacquisition - Vehicle). Following infusions, all rats received a conditioning episode identical to the one given on Day 1. Finally, rats were tested for fear responses across a retention test conducted $14 \mathrm{~d}$ later. The 14-d retention interval was inserted for similar reasons as in Experiment 2. Indeed, a previous study showed that massive extinction transiently impairs context reconditioning (Leung et al. 2007).

\section{Histology}

Figure 1D shows the approximate location of injection cannula tips. A total of eight rats were excluded because of incorrect placement. This yielded the following group sizes: Group Initial Acquisition - Vehicle $(n=6)$, Group Initial Acquisition - APV $(n=6)$, Group Additional Acquisition - Vehicle $(n=6)$, Group Additional Acquisition - APV $(n=6)$, Group Reacquisition - Vehicle $(n=7)$, and Group Reacquisition $\operatorname{APV}(n=6)$.

\section{Behavior}

Levels of conditioned freezing to the context are shown in Figure 5. Conditioning on Day 1 was successful. There were substantial levels of freezing when rats in Groups Reacquisition were returned to the chambers for extinction on Day 2 (data not shown). Extinction was successful as freezing decreased from one extinction session to another $\left(F_{(1,11)}=46.268, P<0.05\right)$, and there were no significant differences between rats in Group Reacquisition Vehicle and Group Reacquisition $-\operatorname{APV}\left(F_{(1,11)}=0.110, P>0.05\right)$. The performances prior to the shock given on Day 13 confirmed that extinction was successful (Fig. 5B, left panel). Rats in Group Reacquisition - Vehicle froze significantly less than rats in Group 
A

\begin{tabular}{|c|c|c|c|c|c|}
\hline Groups & Day 1 & Day 2 - 3 & \multicolumn{2}{|c|}{ Day 4} & Day 5 \\
\hline $\begin{array}{l}\text { Initial Acquisition } \\
\text { (IA) }\end{array}$ & & & $\begin{array}{l}\text { VEH } \\
\text { APV }\end{array}$ & $\mathrm{Cx}+$ & $C x-$ \\
\hline $\begin{array}{l}\text { Additional } \\
\text { Acquisition (AA) }\end{array}$ & $C x+$ & & $\begin{array}{l}\text { VEH } \\
\text { APV }\end{array}$ & $\mathrm{Cx}+$ & $C x-$ \\
\hline $\begin{array}{l}\text { Reacquisition } \\
\text { (RA) }\end{array}$ & $C x+$ & {$\left[2 \times 20^{\prime}\right] \mathrm{Cx}$} & $\begin{array}{l}\text { VEH } \\
\text { APV }\end{array}$ & $\mathrm{Cx}+$ & $C x-$ \\
\hline
\end{tabular}

B

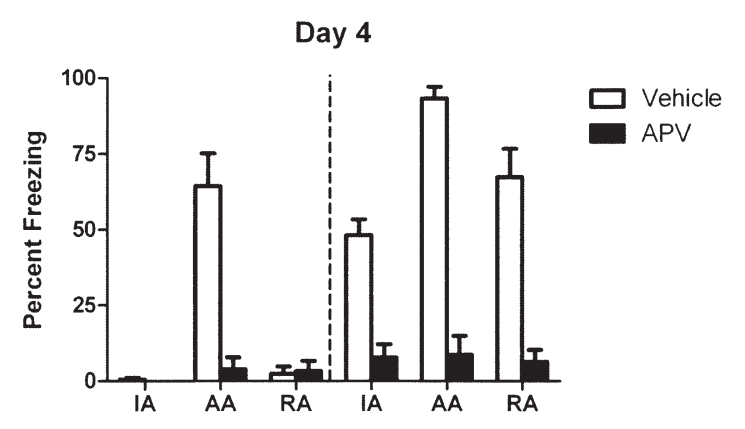

C

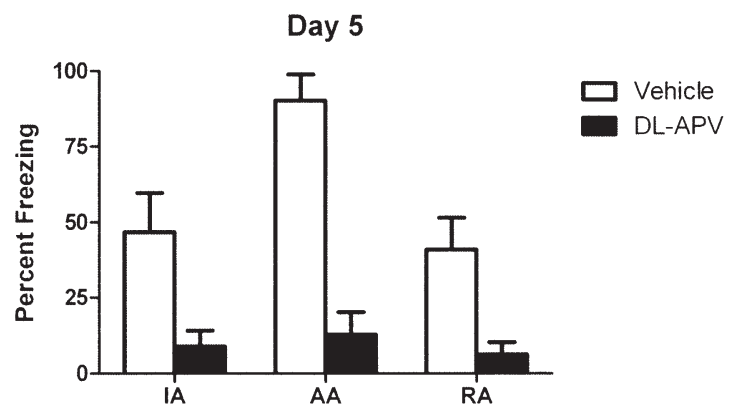

Figure 4. BLA infusion of DL-APV impairs relearning to fear a context extinguished to criterion. $(A)$ Description of the behavioral procedures used in Experiment $3(\mathrm{Cx}+$ indicates shocked exposure to the chambers; $\mathrm{Cx}_{-}$, nonshocked exposure to the chambers; VEH, Vehicle; and APV, DL-APV). (B) All illustrations show the mean and SEM levels of freezing. Rats treated with vehicle before an additional conditioning episode (Group Additional Acquisition - Vehicle) froze more before (left panel) and after (right panel) the shock given on Day 4 than rats that had received criterion extinction (Group Reacquisition - Vehicle) or that were trained to fear a novel context (Group Initial Acquisition Vehicle). BLA infusion of DL-APV suppressed fear responses (Group Initial Acquisition - APV, Group Additional Acquisition - APV, and Group Reacquisition - APV). (C) The retention test data show that DL-APV disrupted learning to fear a novel context, a dangerous context and a context extinguished to criterion (Group Initial Acquisition - APV, Group Additional Acquisition - APV, and Group Reacquisition - APV). The reacquisition of fear responses to a context extinguished to criterion (Group Reacquisition - Vehicle) produced similar fear than the acquisition of fear responses to a novel context (Group Initial Acquisition - Vehicle) but significantly less fear that the additional acquisition of fear responses to a dangerous context (Group Additional Acquisition - Vehicle).

Additional Acquisition - Vehicle $\left(F_{(1,32)}=59.948, P<0.05\right)$ but just as much as did rats in Group Initial Acquisition - Vehicle $\left(F_{(1,32)}=0.001, P>0.05\right)$. Conditioning on Day 1 was successful for rats in Group Additional Acquisition as they spent significantly more time freezing than rats in Group Initial Acquisition Vehicle $\left(F_{(1,32)}=17.445, P<0.05\right)$. DL-APV reduced fear responses during the period prior to the shock. Rats in Group Additional Acquisition - APV froze significantly less than rats in Group
Additional Acquisition - Vehicle. The administration of the shock did not restore fear responses reduced by massive extinction or infusion of DL-APV (Fig. 5B, right panel). Rats in Group Reacquisition - Vehicle froze significantly less than rats in Group Additional Acquisition - Vehicle $\left(F_{(1,32)}=31.738, P<0.05\right)$ but just as much as did rats in Group Initial Acquisition - Vehicle $\left(F_{(1,32)}=2.758, P>0.05\right)$. Rats infused with DL-APV spent significantly less time freezing than rats treated with vehicle $\left(F_{(1,32)}=62.018, P<0.05\right)$. There were no significant differences between the groups of rats treated with DLAPV (Group Initial Acquisition - APV [ $n$ = 6], Group Additional Acquisition - APV, and Group Reacquisition - APV; Fs < 0.5).

The test data (Fig. 5C) indicated that DL-APV infused in the BLA impaired the acquisition of fear responses to a novel context, a feared context, and a massively extinguished context. Rats in Group Initial Acquisition - APV, Group Additional Acquisition - APV, and Group Reacquisition - APV froze significantly less than rats in Group Initial Acquisition - Vehicle, Group Additional Acquisition - Vehicle, and Group Reacquisition - Vehicle $\left(F_{(1,32)}=24.990, P<0.05\right)$. There were no significant differences between rats treated with DL-APV $(F s<1)$. Rats reconditioned under vehicle after massive extinction (Group Reacquisition - Vehicle) showed similar levels of freezing as rats that had received one conditioning episode under vehicle but no extinction (Group Initial Acquisition - Vehicle) $\left(F_{(1,32)}=0.192, P>0.05\right)$. However, their levels of freezing were significantly lower than the ones displayed by rats in Group Additional Acquisition - Vehicle $\left(F_{(1,32)}=\right.$ 43.158, $P<0.05)$.

\section{Discussion}

The present series of experiments examined the effects of infusing DL-APV in the BLA on learning and relearning context-conditioned fear. The main finding is that neither stimulus familiarity nor task familiarity removes the ability of the NMDAr antagonist to impair context fear conditioning. DL-APV disrupted the development of fear responses to a novel (Experiments 1 and 2), a moderately familiar (Experiment 1), and a massively familiar context (Experiment 2). A similar impairment was observed when the context had already been feared. That is, DL-APV disrupted additional conditioning of an already feared context (Experiments 3 and 4), as well as reconditioning of a context extinguished to criterion (Experiment 3 ) or of a massively extinguished context (Experiment 4). Importantly, DL-APV infusion in the BLA reduced fear responses across context alone (i.e., pre-shock freezing) and context-shock presentations (i.e., post-shock freezing) in all our experiments. 
A

\begin{tabular}{|c|c|c|c|c|c|}
\hline Groups & Day 1 & Day 2 - 12 & \multicolumn{2}{|c|}{ Day 13} & Day 27 \\
\hline $\begin{array}{l}\text { Initial Acquisition } \\
\text { (IA) }\end{array}$ & & & $\begin{array}{l}\text { VEH } \\
\text { APV }\end{array}$ & $C x+$ & $C x-$ \\
\hline $\begin{array}{l}\text { Additional } \\
\text { Acquisition (AA) }\end{array}$ & $\mathrm{Cx}+$ & & $\begin{array}{l}\text { VEH } \\
\text { APV }\end{array}$ & $\mathrm{Cx}+$ & Cx - \\
\hline $\begin{array}{l}\text { Re-acquisition } \\
\text { (RA) }\end{array}$ & $\mathrm{Cx}+$ & {$\left[2 \times 20^{\prime}\right] \mathrm{Cx}-$} & $\begin{array}{l}\text { VEH } \\
\text { APV }\end{array}$ & $C x+$ & $C x-$ \\
\hline
\end{tabular}

B

Day 13

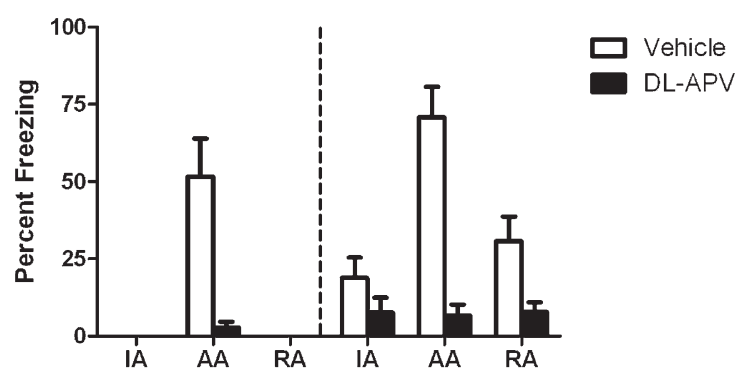

C

Day 27

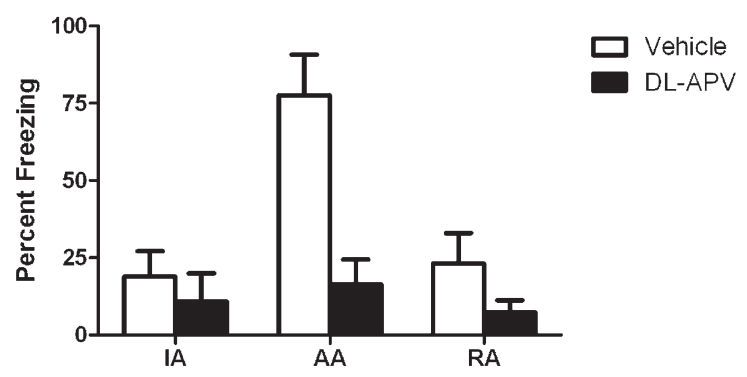

Figure 5. BLA infusion of DL-APV impairs relearning to fear a massively extinguished context. $(A)$ Description of the behavioral procedures used in Experiment $4(\mathrm{Cx}+$ indicates shocked exposure to the chambers; $\mathrm{Cx}-$, nonshocked exposure to the chambers; VEH, Vehicle; and APV, DL-APV). (B) All illustrations show the mean and SEM levels of freezing. Rats treated with vehicle before an additional conditioning episode (Group Additional Acquisition - Vehicle) froze more before (left panel) and after (right panel) the shock given on Day 13 than rats that had received massive extinction (Group Reacquisition - Vehicle) or that were trained to fear a novel context (Group Initial Acquisition Vehicle). Massive extinction impaired levels of post-shock freezing (right panel; Group Reacquisition Vehicle vs. Group Initial Acquisition - Vehicle). BLA infusion of DL-APV suppressed fear responses (Group Initial Acquisition - APV, Group Additional Acquisition - APV, and Group Reacquisition - APV). (C) The retention test data show that DL-APV disrupted learning to fear a novel context, a dangerous context, and a context massively extinguished (Group Initial Acquisition - APV, Group Additional Acquisition - APV, and Group Reacquisition - APV). The reacquisition of fear responses to a massively extinguished context (Group Reacquisition - Vehicle) produced similar fear than the acquisition of fear responses to a novel context (Group Initial Acquisition - Vehicle) but significantly less fear that the additional acquisition of fear responses to a dangerous context (Group Additional Acquisition Vehicle).

Activation of molecular mechanisms within the BLA is necessary for the learning produced by the pairing of a context with an aversive foot shock. As found previously (Maren et al. 1996; Lee and Kim 1998; Matus-Amat et al. 2007), rats that had been infused with DL-APV in the BLA prior to being trained to fear a novel context froze significantly less across test than rats infused with vehicle (Experiments 1 to 4 ). The amount of pre-exposure to a context affects the acquisition of fear responses associated with this context but does not remove the ability of DL-APV to disrupt acquisition. When infused with vehicle in the BLA, rats froze significantly more across test if they had been briefly pre-exposed to the context (Experiment 1) (Fanselow 1990; Kiernan and
Westbrook 1993; Wiltgen et al. 2001). However, this facilitation is prevented by local infusion of DL-APV (Matus-Amat et al. 2007). Rats treated with the NMDAr antagonist in the BLA showed very low levels of fear responses across test whether they had been conditioned in a briefly pre-exposed context or in a novel context (Experiment 1). Increasing the amount of pre-exposures typically impairs the development of context-conditioned fear, a phenomenon known as latent inhibition (Schmajuk et al. 2001). This impairment is transient as fear responses recover with the passage of time (Killcross et al. 1998; Leung et al. 2007). Rats shocked in a massively pre-exposed context showed few if any fear responses across the post-shock period in comparison to the substantial amounts of fear responses shown by rats shocked in a novel context, indicating a latent inhibitory effect of massive pre-exposure on conditioned fear responses. Nevertheless, vehicle-treated rats that had been massively pre-exposed to the context froze just as much at the 14-d retention test as did vehicle-treated rats that had not been pre-exposed (Experiment 2). DL-APV eliminated the recovery of fear responses across the retention interval. Rats infused with the NMDAr antagonist in the BLA showed little or no fear responses on the retention test regardless of whether they had been shocked in a novel or massively pre-exposed context (Experiment 2). Taken together, these results suggest that BLA infusion of DLAPV disrupts the acquisition of fear responses to a novel context, a moderately familiar context, and a massively familiar context.

Additional acquisition of fear responses to a context, like initial acquisition, requires activation of molecular mechanisms within the BLA. Rats that had been retrained to fear a dangerous context under BLA infusion of DL-APV froze significantly less across test than control rats (Experiments 3 and 4). Further, the ability of the NMDAr antagonist to disrupt subsequent training did not depend on the delay between the two conditioning episodes (i.e., 3 or $12 \mathrm{~d}$ ) or between the last conditioning episode and test (i.e., 1 or $14 \mathrm{~d}$ ). Reacquisition of fear responses to an extinguished context is influenced by the amount of extinction and is impaired by BLA infusion of DL-APV. When infused with vehicle, rats retrained to fear a context extinguished to criterion exhibited as much fear response across test as rats trained to fear a novel context, but significantly less fear than rats retrained to fear a dangerous context (Experiment 3). This last finding is inconsistent with results from a previous study showing that fear responses that have been extinguished to criterion are reacquired more rapidly than they are acquired (Leung et al. 2007). Although the reason for this discrepancy remains unclear, we suggest that rapid reacquisition 
of extinguished fear responses is very sensitive to the amount of extinction. A detailed analysis of the two studies revealed that fear responses at the end of extinction were more depressed in our experiment (where reacquisition was mildly impaired) than in those reported previously (where rapid reacquisition was observed). In contrast to criterion extinction, massive extinction exerts a transient impairment on the expression of subsequent context-conditioned fear: Freezing is depressed $1 \mathrm{~d}$ after reconditioning, but freezing recovers when tested after a long retention interval (Leung et al. 2007). On the test conducted $14 \mathrm{~d}$ after reconditioning, rats retrained to fear a massively extinguished context froze just as much as did rats that had been shocked in a novel context (Experiment 4). DL-APV disrupted reacquisition of fear responses to an extinguished context. Rats retrained to fear a context extinguished to criterion under the influence of the NMDAr antagonist in the BLA froze significantly less across test than control rats (Experiment 3). A similar impairment was observed for reacquisition after massive extinction (Experiment 4). Thus, DL-APV infused in the BLA prevents the redevelopment of fear responses to a dangerous context, a context extinguished to criterion, and a massively extinguished context.

BLA infusion of DL-APV suppresses the expression of contextconditioned fear (Maren et al. 1996; Lee and Kim 1998; Lee et al. 2001; Matus-Amat et al. 2007; Laurent et al. 2008). When under the influence of the NMDAr antagonist, rats exhibited less fear responses than vehicle-treated rats across context alone or contextshock presentations (Experiments 1 to 4). This suggests that DL-APV disrupted basal synaptic transmission in the BLA (Li et al. 1995; Maren and Fanselow 1995; Bauer et al. 2002). There is evidence that this disruption is mediated by the $\mathrm{L}$ isomer, and not the D isomer, that constitutes DL-APV (Matus-Amat et al. 2007). It is therefore unlikely that a lower dose of DL-APV would produce different effects to the ones we observed in the current study. Consequently, we cannot exclude the possibility that the NMDAr antagonist prevented learning and relearning context-conditioned fear via a disruption of neuronal activity in the BLA rather than a blockade of NMDAr-mediated synaptic plasticity (Lee and Kim 1998). Nevertheless, it is likely that a more selective NMDAr antagonist, such as ifenprodil, which blocks NMDAr containing the NR2B subunit but does not disrupt neuronal activity in the BLA (Rodrigues et al. 2001; Bauer et al. 2002; Matus-Amat et al. 2007; Walker and Davis 2008), would produce deficits similar to the ones reported in the present study. For instance, it has been shown that BLA infusion of D-APV spares fear expression but disrupts the acquisition of fear responses to a moderately familiar context (MatusAmat et al. 2007). Further, a recent study has shown that acquisition of conditioned fear can occur in the absence of NMDAr-mediated plasticity within the BLA when rats are subjected to multiple CS-shock-US pairings but not when rats are subjected to the number of trials used here (Pistell and Falls 2008). Finally, we have shown that relearning to inhibit context-conditioned fear responses occurs when neuronal activity in the BLA is disrupted by infusion of DL-APV, but relearning this inhibition is impaired by BLA infusion of ifenprodil (Laurent et al. 2008). These contrasting effects suggest that activation of NMDAr containing the NR2B subunit in the BLA is critical for relearning to inhibit fear responses, but that inactivation of basal activity in the BLA and the corresponding disruption of fear pathways allow other structures (e.g., the prefrontal cortex) to compensate and mediate relearning inhibition.

Regardless of the possible mechanisms by which DL-APV disrupted learning and relearning context-conditioned fear, the present results are consistent with contemporary models of context fear conditioning (Fanselow and LeDoux 1999; Maren 2001b; Pare et al. 2004). According to these models, the hippocampus serves to bind the various individual elements (e.g., floor texture, illumination, odors, and so on) into a configural repre- sentation of the context (Rudy et al. 2004). Information about this representation of the context CS and the foot shock US converge in the BLA leading to potentiation of the synaptic transmission in an NMDAr-dependent manner assumed to underlie the formation of a context CS-shock-US memory. Consistent with these models, blockade of NMDAr or disruption of neuronal activity within the hippocampus spares acquisition of fear responses to a pre-exposed context, suggesting that once the configural representation has been formed it no longer requires hippocampal-dependent activity for its association with shock (Matus-Amat et al. 2004, 2007). However, in line with previous studies (Matus-Amat et al. 2007), we found that similar manipulations within the BLA disrupt learning to fear a moderately familiar context. Further, we have shown that such manipulations in the BLA also disrupt learning to fear a highly familiar context as well as relearning to fear a dangerous context or an extinguished context but, as noted previously, only when the extinguished or the dangerous context receives a limited amount of pairings with the shock US (Maren 1999, 2001a; Ponnusamy et al. 2007; Pistell and Falls 2008). Thus, both neuronal activity and synaptic plasticity in the BLA are necessary for learning and relearning context-conditioned fear. Neuronal activity and synaptic plasticity in the BLA are also necessary to learn to inhibit context-conditioned fear in extinction. However, the roles of neuronal activity and synaptic plasticity in relearning to inhibit fear responses can be dissociated: Disruption of neuronal activity allows relearning, whereas disruption of synaptic plasticity disrupts this relearning (Laurent et al. 2008). These conclusions are consistent with the view that the amygdala is the key structure underlying the formation of fear memories, whereas inhibiting those memories involve complex interactions between several brain regions, including the amygdala, the medial prefrontal cortex, and the hippocampus (Quirk and Mueller 2008).

\section{Materials and Methods}

\section{Subjects}

Subjects were 180 experimentally naïve male Wistar rats (Rattus norvegicus). They were obtained from a local supplier (Gore Hill Research Laboratories, Sydney, New South Wales, Australia) and weighed between 280 and $350 \mathrm{~g}$. They were housed in plastic boxes $(22 \mathrm{~cm}$ high $\times 65 \mathrm{~cm}$ long $\times 40 \mathrm{~cm}$ wide) located in a climate-controlled colony room under natural lighting. There were eight rats per box with food and water continuously available. Three days after arrival in the laboratory, rats were handled each day for $4 \mathrm{~d}$. The experimental procedures were approved by the Animal Ethics Committee at the University of New South Wales and conducted in accordance with the National Institutes of Health Guidelines for the Care and Use of Laboratory Animals (publication DHHS NIH 86-23). All experiments occurred between 7:00 a.m. and 10:00 p.m.

\section{Drugs}

The selective NMDA receptor antagonist DL-APV (Sigma) was dissolved in $0.9 \%(\mathrm{w} / \mathrm{v})$ nonpyrogenic saline to obtain a final concentration of $2.5 \mu \mathrm{g} / 0.3 \mu \mathrm{L}$. Nonpyrogenic saline was used to control for any effect of the infusion procedures per se. The dose of DL-APV was selected on the basis of previous investigations (Lee and Kim 1998; Lee et al. 2001; Laurent et al. 2008).

\section{Surgery and microinjections}

Rats received intraperitoneal (i.p.) injections of $1.3 \mathrm{~mL} / \mathrm{kg}$ of the anesthetic ketamine (Ketapex; Apex Laboratories) at a concentration of $100 \mathrm{mg} / \mathrm{mL}$ and of $0.3 \mathrm{~mL} / \mathrm{kg}$ of the muscle relaxant xylazine (Rompun; Bayer) at a concentration of $20 \mathrm{mg} / \mathrm{mL}$. Anaesthetized rats were then mounted on a stereotaxic apparatus (Kopf Instruments), and 26-gauge guide cannulas (Plastics One) were implanted through holes drilled in both hemispheres of the skull. The tips of the guide cannulas were aimed bilaterally at the basolateral amygdala using the following coordinates: $2.3 \mathrm{~mm}$ 
posterior to bregma, $4.8-5 \mathrm{~mm}$ lateral to the midline, and $7.7-8 \mathrm{~mm}$ ventral to the skull. The guide cannulas were maintained in position with dental cement and dummy cannulas were kept in each guide at all times except during microinjections. Immediately after the surgical procedure, rats were injected i.p. with a prophylactic $(0.3$ $\mathrm{mL}$ ) dose of $300 \mathrm{mg} / \mathrm{kg}$ solution of procaine penicillin. Rats were allowed $4 \mathrm{~d}$ to recover from surgery, during which time they were handled and weighed daily.

DL-APV $(2.5 \mu \mathrm{g} / 0.3 \mu \mathrm{L})$ and vehicle were infused bilaterally in the basolateral amygdala by inserting a 33-gauge internal cannula into the guide cannula. The internal cannula was connected to a $25-\mu \mathrm{L}$ glass syringe attached to an infusion pump (Harvard Apparatus) and projected an additional $1 \mathrm{~mm}$ ventral to the tip of the guide cannula. A total volume of $0.3 \mu \mathrm{L}$ was delivered at a rate of $0.1 \mu \mathrm{L} / \mathrm{min}$. The internal cannula remained in place for 1 min longer after the infusions and was then removed. On the day before infusions, the dummy cannula was removed and the infusion pump was turned on for $3 \mathrm{~min}$ in order to familiarize the rats with the procedure and thereby minimize any stress produced by this procedure when infusions occurred. All infusions occurred in a separate room from the colony room and the experimental room.

\section{Histology}

Subsequent to behavioral testing, subjects implanted with cannulas received a lethal dose of sodium pentobarbital and their brains were removed and frozen. Unfixed brains were sectioned coronally at $40 \mu \mathrm{m}$ through the BLA. Every third section was collected on a slide, and the sections were stained with cresyl violet. The approximate location of injection cannulas tips was determined under a microscope by a trained observer who was unaware of the subjects' group designations using the boundaries defined by the Paxinos and Watson atlas (Paxinos and Watson 2007). Subjects with inaccurate guide cannula placements or with extensive damage to the BLA were excluded from the statistical analysis.

\section{Apparatus}

Four chambers, each measuring $20 \mathrm{~cm}$ height $\times 21 \mathrm{~cm}$ length $\times$ $23 \mathrm{~cm}$ width were used for pre-exposure, fear conditioning, extinction training, and testing. The front and rear walls of these chambers, as well as the hinged lid, were constructed of Perspex, and the end walls were made of stainless steel. The floor in each chamber consisted of stainless steel rods, $2 \mathrm{~mm}$ in diameter, spaced $10 \mathrm{~mm}$ apart (center to center). The US was a 1-sec, 0.8-mA unscrambled AC 50-Hz foot shock from a constant-current generator that was delivered to the floor of each chamber. The current available to each floor could be adjusted using an in-line milliampere meter. The floor of each chamber was $5 \mathrm{~cm}$ above a tray of paper pellet bedding (Fibrecycle) that was changed between rats. After removal of a rat, the floor of each chamber was cleaned with a solution of acetic acid (1\%) to eliminate any residue and provide a distinctive odor. The four chambers were located within separate compartments of a wooden cabinet. The door of each compartment was kept open to permit observation of the rat. The room that contained the experimental chambers was illuminated by four $60-\mathrm{W}$ standard incandescent lights located in the ceiling. All experimental sessions were recorded on videotape via a camera mounted on a wall opposite the chambers. The camera was connected to a monitor and video recorder located in an adjacent room.

\section{Behavioral procedures}

\section{Experiment 1: BLA infusion of DL-APV impairs learning to fear a briefly pre-exposed context}

From Day 1 to Day 4, rats in Groups Brief Pre-exposure were placed in conditioning chambers for 2 min each day. Rats in Groups No Pre-exposure were not exposed to the chambers but were handled. Across all experiments, control rats were handled rather than preexposed to a control context in order to avoid any generalization between the control context and the experimental context. Indeed, generalization would have significantly altered the outcome of manipulating stimulus or task familiarity. On Day 5, half of the rats in each group (Group No Pre-exposure - APV and Group Brief Pre-exposure - APV) received an infusion of DL-APV in the BLA $(2.5 \mu \mathrm{g} / 0.3 \mu \mathrm{L})$, whereas the remaining rats (Group No Pre-exposure - Vehicle and Group Brief Pre-exposure Vehicle) received an infusion of vehicle. Immediately after infusions, rats were placed in the chambers and administered a foot shock $(0.8 \mathrm{~mA}, 1 \mathrm{sec}) 1 \mathrm{~min}$ later. They remained in the chambers for a further $2 \mathrm{~min}$ and were then removed and returned to their home cages. Six hours after this conditioning episode, rats that had been infused in the BLA with vehicle now received DL-APV (Group No Pre-exposure - Vehicle and Group Brief Pre-exposure - Vehicle), and rats that had been infused with DL-APV now received vehicle (Group No Pre-exposure APV and Group Brief Pre-exposure - APV). These counterbalanced infusions were used to control for any effects of DL-APV per se on responding across the subsequent test. Finally, all rats were tested drug-free across a 5-min nonshocked exposure to the chambers on Day 6.

\section{Experiment 2: BLA infusion of DL-APV impairs learning to fear a massively pre-exposed context}

Rats in Groups Massive Pre-exposure received twice daily (a.m. and p.m.) nonshocked exposure to the chambers from Day 1 to Day 11. Each exposure was $20 \mathrm{~min}$ in duration. Rats in Groups No Preexposure were not exposed to the chambers but were handled on each day. On Day 12, rats in Group No Pre-exposure - APV and Group Massive Pre-exposure - APV received an infusion of DLAPV $(2.5 \mu \mathrm{g} / 0.3 \mu \mathrm{L})$ in the BLA, whereas those in Group No Preexposure - Vehicle and Group Massive Pre-exposure - Vehicle received an infusion of vehicle. Then all rats were shocked in the chamber in the manner described in Experiment 1. Counterbalanced infusions were given $6 \mathrm{~h}$ later in the manner described. All rats were tested drug-free $14 \mathrm{~d}$ later in the manner described previously. Test occurred $14 \mathrm{~d}$ later as massive pre-exposures to a to-be-shocked context produce a transient impairment of fear responses that is removed by the passage of time (Killcross et al. 1998; Leung et al. 2007).

\section{Experiment 3: BLA infusion of DL-APV impairs relearning to fear a context extinguished to criterion}

On Day 1, rats in Groups Additional Acquisition and Reacquisition were shocked in the chambers in the manner described. Rats in Group Initial Acquisition were handled. From Day 2 to Day 3, rats in Groups Reacquisition received twice daily (a.m. and p.m.) exposure to the chambers in the absence of the shock. Each exposure lasted for $20 \mathrm{~min}$. This was sufficient to reach a selected extinction criterion that was defined as less than $5 \%$ of time spent freezing across the initial minute of exposure. Rats in Groups Initial Acquisition and Additional Acquisition did not receive extinction but were handled. On Day 4, half of the rats in each group (Group Initial Acquisition - APV, Group Additional Acquisition - APV, Group Reacquisition - APV) received an infusion of DL-APV in the BLA $(2.5 \mu \mathrm{g} / 0.3 \mu \mathrm{L})$, whereas the remaining rats (Group Initial Acquisition - Vehicle, Group Additional Acquisition - Vehicle, Group Reacquisition - Vehicle) received vehicle. Immediately after infusions, all rats underwent the same conditioning episode as on Day 1. Six hours later, counterbalanced infusion of either DL-APV or vehicle was performed. On Day 5, rats were tested drug-free in the chambers in the manner described.

Experiment 4: BLA infusion of DL-APV impairs relearning to fear a massively extinguished context

On Day 1, rats in Groups Reacquisition and Additional Acquisition were shocked in the manner described whereas rats in Groups Initial Acquisition were handled. Rats in Groups Reacquisition then received twice daily (a.m. and p.m.) nonshocked exposure to the chambers from Day 2 to Day 12. Each exposure was 20 min in duration. Rats in Groups Initial Acquisition and Additional Acquisition were not exposed to the chambers but were handled. On Day 13, rats in Group Initial Acquisition - APV, Group Additional Acquisition - APV, and Group Reacquisition - APV received an infusion of DL-APV $(2.5 \mu \mathrm{g} / 0.3 \mu \mathrm{L})$ in the BLA, 
whereas those in Group Initial Acquisition - Vehicle, Group Additional Acquisition - Vehicle, and Group Reacquisition - Vehicle received an infusion of vehicle. Immediately after infusions, rats underwent a conditioning episode identical to the one given on Day 1. Counterbalanced infusions were given $6 \mathrm{~h}$ later in the manner described. Finally, all rats were tested drug-free $14 \mathrm{~d}$ later in the manner described previously. Test occurred $14 \mathrm{~d}$ later as massive extinction, like massive pre-exposures, transiently impairs relearning of contextual fear responses (Leung et al. 2007).

\section{Scoring and statistics}

Freezing was defined as the absence of all movements, except those related to breathing (Blanchard and Blanchard 1969). The behavior of each rat was recorded on videotape, and freezing was rated with a time-sampling procedure in which each rat was observed every $2 \mathrm{sec}$ and scored as either freezing or moving. A percentage score was calculated for the proportion of the total observation that each rat spent freezing. Freezing was rated by two observers, one of whom was unaware of the subject's group designation. There was a high degree of agreement between the two observers: The Pearson product moment correlation between their rating was $>0.95$. The test data were analyzed in each experiment by a set of planned nonorthogonal contrasts that controlled the family-wise error rate using the Bonferroni inequality procedure (Harris 1994). Significance was set at the 0.05 level for each family of contrasts tested.

\section{References}

Bannerman, D.M., Good, M.A., Butcher, S.P., Ramsay, M., and Morris, R.G. 1995. Distinct components of spatial learning revealed by prior training and NMDA receptor blockade. Nature 378: 182-186.

Bauer, E.P., Schafe, G.E., and Ledoux, J.E. 2002. NMDA receptors and L-type voltage-gated calcium channels contribute to long-term potentiation and different components of fear memory formation in the lateral amygdala. J. Neurosci. 22: 5239-5249.

Berman, D.E. and Dudai, Y. 2001. Memory extinction, learning anew, and learning the new: Dissociations in the molecular machinery of learning in cortex. Science 291: 2417-2419.

Blair, H.T., Schafe, G.E., Bauer, E.P., Rodrigues, S.M., and LeDoux, J.E. 2001. Synaptic plasticity in the lateral amygdala: A cellular hypothesis of fear conditioning. Learn. Mem. 8: 229-242.

Blanchard, R.J. and Blanchard, D.C. 1969. Crouching as an index of fear. J. Comp. Physiol. Psychol. 67: 370-375.

Campeau, S., Miserendino, M.J., and Davis, M. 1992. Intra-amygdala infusion of the $N$-methyl-d-aspartate receptor antagonist AP5 blocks acquisition but not expression of fear-potentiated startle to an auditory conditioned stimulus. Behav. Neurosci. 106: 569-574.

Fanselow, M.S. 1990. Factors governing one trial contextual fear conditioning. Anim. Learn. Behav. 18: 264-270.

Fanselow, M.S. and LeDoux, J.E. 1999. Why we think plasticity underlying Pavlovian fear conditioning occurs in the basolateral amygdala. Neuron 23: 229-232.

Fendt, M. 2001. Injections of the NMDA receptor antagonist aminophosphonopentanoic acid into the lateral nucleus of the amygdala block the expression of fear-potentiated startle and freezing. J. Neurosci. 21: 4111-4115.

Harris, R.J. 1994. ANOVA: An analysis of variance primer. Peacock, Itsac, IL.

Jasnow, A.M., Cooper, M.A., and Huhman, K.L. 2004. N-methyl-D-aspartate receptors in the amygdala are necessary for the acquisition and expression of conditioned defeat. Neuroscience 123: 625-634.

Kiernan, M.J. and Westbrook, R.F. 1993. Effects of exposure to a to-beshocked environment upon the rat's freezing response: Evidence for facilitation, latent inhibition, and perceptual learning. Q. J. Exp. Psychol. B 46: 271-288.

Killcross, A.S., Kiernan, M.J., Dwyer, D., and Westbrook, R.F. 1998. Effects of retention interval on latent inhibition and perceptual learning. Q. J. Exp. Psychol. B 51: 59-74.

Laurent, V., Marchand, A.R., and Westbrook, R.F. 2008. The basolateral amygdala is necessary for learning but not relearning extinction of context conditioned fear. Learn. Mem. 15: 304-314.

Lee, H. and Kim, J.J. 1998. Amygdalar NMDA receptors are critical for new fear learning in previously fear-conditioned rats. J. Neurosci. 18: 8444-8454.

Lee, H.J., Choi, J.S., Brown, T.H., and Kim, J.J. 2001. Amygdalar NMDA receptors are critical for the expression of multiple conditioned fear responses. J. Neurosci. 21: 4116-4124.

Leung, H.T., Bailey, G.K., Laurent, V., and Westbrook, R.F. 2007. Rapid reacquisition of fear to a completely extinguished context is replaced by transient impairment with additional extinction training. J. Exp. Psychol. Anim. Behav. Process. 33: 299-313.

Li, X.F., Phillips, R., and LeDoux, J.E. 1995. NMDA and non-NMDA receptors contribute to synaptic transmission between the medial geniculate body and the lateral nucleus of the amygdala. Exp. Brain Res. 105: 87-100.

Maren, S. 1999. Neurotoxic basolateral amygdala lesions impair learning and memory but not the performance of conditional fear in rats. J. Neurosci. 19: 8696-8703.

Maren, S. 2001a. Is there savings for pavlovian fear conditioning after neurotoxic basolateral amygdala lesions in rats? Neurobiol. Learn. Mem. 76: $268-283$.

Maren, S. 2001b. Neurobiology of Pavlovian fear conditioning. Annu. Rev. Neurosci. 24: 897-931.

Maren, S. and Fanselow, M.S. 1995. Synaptic plasticity in the basolateral amygdala induced by hippocampal formation stimulation in vivo. J. Neurosci. 15: 7548-7564.

Maren, S., Aharonov, G., Stote, D.L., and Fanselow, M.S. 1996. N-methyl-Daspartate receptors in the basolateral amygdala are required for both acquisition and expression of conditional fear in rats. Behav. Neurosci. 110: $1365-1374$.

Martin, S.J., Grimwood, P.D., and Morris, R.G. 2000. Synaptic plasticity and memory: An evaluation of the hypothesis. Annu. Rev. Neurosci. 23: 649-711.

Matus-Amat, P., Higgins, E.A., Barrientos, R.M., and Rudy, J.W. 2004. The role of the dorsal hippocampus in the acquisition and retrieval of context memory representations. J. Neurosci. 24: 2431-2439.

Matus-Amat, P., Higgins, E.A., Sprunger, D., Wright-Hardesty, K., and Rudy, J.W. 2007. The role of dorsal hippocampus and basolateral amygdala NMDA receptors in the acquisition and retrieval of context and contextual fear memories. Behav. Neurosci. 121: 721-731.

Miserendino, M.J., Sananes, C.B., Melia, K.R., and Davis, M. 1990. Blocking of acquisition but not expression of conditioned fear-potentiated startle by NMDA antagonists in the amygdala. Nature 345: 716-718.

Morris, R.G. 1989. Synaptic plasticity and learning: Selective impairment of learning rats and blockade of long-term potentiation in vivo by the $N$-methyl-D-aspartate receptor antagonist AP5. J. Neurosci. 9: 3040-3057.

Myers, K.M. and Davis, M. 2007. Mechanisms of fear extinction. Mol. Psychiatry 12: 120-150.

Pare, D., Quirk, G.J., and Ledoux, J.E. 2004. New vistas on amygdala networks in conditioned fear. J. Neurophysiol. 92: 1-9.

Paxinos, G. and Watson, C. 2007. The rat brain in stereotaxic coordinates. Academic, Sydney, Australia.

Pistell, P.J. and Falls, W.A. 2008. Extended fear conditioning reveals a role for both $N$-methyl-D-aspartic acid and non- $N$-methyl-D-aspartic acid receptors in the amygdala in the acquisition of conditioned fear. Neuroscience 155: 1011-1020.

Ponnusamy, R., Poulos, A.M., and Fanselow, M.S. 2007. Amygdaladependent and amygdala-independent pathways for contextual fear conditioning. Neuroscience 147: 919-927.

Quinn, J.J., Loya, F., Ma, Q.D., and Fanselow, M.S. 2005. Dorsal hippocampus NMDA receptors differentially mediate trace and contextual fear conditioning. Hippocampus 15: 665-674.

Quirk, G.J. and Mueller, D. 2008. Neural mechanisms of extinction learning and retrieval. Neuropsychopharmacology 33: 56-72.

Riedel, G., Platt, B., and Micheau, J. 2003. Glutamate receptor function in learning and memory. Behav. Brain Res. 140: 1-47.

Rodrigues, S.M., Schafe, G.E., and LeDoux, J.E. 2001. Intra-amygdala blockade of the NR2B subunit of the NMDA receptor disrupts the acquisition but not the expression of fear conditioning. J. Neurosci. 21: 6889-6896.

Rudy, J.W., Huff, N.C., and Matus-Amat, P. 2004. Understanding contextual fear conditioning: Insights from a two-process model. Neurosci. Biobehav. Rev. 28: 675-685.

Sanders, M.J. and Fanselow, M.S. 2003. Pre-training prevents context fear conditioning deficits produced by hippocampal NMDA receptor blockade. Neurobiol. Learn. Mem. 80: 123-129.

Schmajuk, N.A., Cox, L., and Gray, J.A. 2001. Nucleus accumbens, entorhinal cortex and latent inhibition: A neural network model. Behav. Brain Res. 118: 123-141.

Walker, D.L. and Davis, M. 2008. Amygdala infusions of an NR2B-selective or an NR2A-preferring NMDA receptor antagonist differentially influence fear conditioning and expression in the fear-potentiated startle test. Learn. Mem. 15: 67-74.

Wiltgen, B.J., Sanders, M.J., Behne, N.S., and Fanselow, M.S. 2001. Sex differences, context preexposure, and the immediate shock deficit in Pavlovian context conditioning with mice. Behav. Neurosci. 115: 26-32.

Received September 11, 2008; accepted in revised form November 2, 2008. 


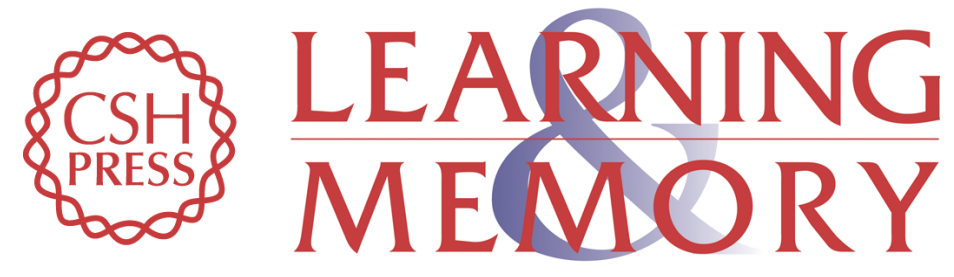

\section{Infusion of the NMDA receptor antagonist, DL-APV, into the basolateral amygdala disrupts learning to fear a novel and a familiar context as well as relearning to fear an extinguished context}

Vincent Laurent and R. Frederick Westbrook

Learn. Mem. 2009, 16:

Access the most recent version at doi:10.1101//m.1218709

References This article cites 40 articles, 13 of which can be accessed free at: http://learnmem.cshlp.org/content/16/1/96.full.html\#ref-list-1

License

Email Alerting Receive free email alerts when new articles cite this article - sign up in the box at the Service top right corner of the article or click here. 